\title{
Differences between the sexes in athletes' body composition and lower limb bioimpedance values
}

\author{
Gabriele Mascherini \\ Jorge Castizo-Olier \\ Alfredo Irurtia \\ Cristian Petri \\ Giorgio Galanti \\ 1 Sports and Exercise Medicine Unit, Department of \\ Experimental and Clinic Medicine, University of \\ Florence, Italy \\ 2 INEFC-Barcelona Sports Sciences Research \\ Group, National Institute of Physical Education of \\ Catalonia, University of Barcelona, Barcelona, \\ Spain
}

Corresponding author:

Gabriele Mascherini

Sports and Exercise Medicine Unit

Department of Experimental and Clinic Medicine, University of Florence, Italy

E-mail: gabriele.mascherini@unifi.it

\section{Summary}

Introduction: The differences between the sexes in body composition are well established, although sports activity at an elite level seems to reduce them. The aim of this study is a comparison of the sexes in terms of athletes' body composition with a three-compartment model and a localized bioimpedance analysis in elite soccer players.

Methods: 18 female and 18 male elite soccer players of the same age were matched (female $=26.2 \pm 2.4$, male $26.9 \pm 2.5 ; p=0.87$ ). An assessment of body composition was performed through the integration of anthropometrics parameters, skinfold thickness and bioimpedance data. The evaluations were carried out in the morning on a group of athletes who were in a rested condition, having not exercised in the previous 12 hours and having fasted for breakfast.

Results: A body composition assessment shows higher values in females for hip circumference/ height (female: $0.55 \pm 0.03$, male: $0.52 \pm 0.02$; $p<0.01$ ) and fat mass index (female: $3.7 \pm 0.7 \mathrm{~kg} / \mathrm{m}^{2}$, male: $2.4 \pm 0.4 \mathrm{~kg} / \mathrm{m}^{2} ; \mathrm{p}<0.001$ ), while there is no difference between the genders in the extra cellular mass index (female: $7.1 \pm 1.2 \mathrm{~kg} / \mathrm{m}^{2}$, male: $7.6 \pm 0.4$ $\mathrm{kg} / \mathrm{m}^{2} ; \mathrm{p}=0.11$ ). A localized bioimpedance analysis describes well-defined differences in the thighs, while in the calves these differences are reversed for the reactance values.
Conclusion: Sports activity seems to slightly reduce differences in the whole body. The different adaption at the same physical effort appears to be mainly related to cellular mass. This study shows for the first time localized bioimpedance values in female athletes.

Level of evidence: II b.

KEY WORDS: body composition, extracellular mass, $L$ BIA, soccer players.

\section{Introduction}

Interest in the study of humans' body composition is growing steadily in terms of research and clinical scope, as has been demonstrated by an increase in the scientific literature over the past decade. Body composition evaluation has too often been limited to anthropometric parameters such as body weight and circumference, as the study of body composition attempts to partition and quantify body mass into its basic components ${ }^{1}$. Over the past century, many techniques and equations have been proposed, but all have some inherent problems: to date, there is no universally applicable criterion or gold standard methodology for body composition assessment ${ }^{1-3}$.

Body composition applications are in a clinical setting in the assessment of cardiovascular risk and in sport in order to optimize the performance of athletes, where excess body fat may affect the result: this aspect is of considerable interest to scientists, athletes and coaches ${ }^{4}$. Soccer players in particular show a body fat mass percentage of $10-18 \%$ in males and $13-18 \%$ in females ${ }^{5}$.

While there are rather substantial physiological differences between the average male and the average female $^{6}$, the hypothesis that these differences decrease when comparisons are made between highly trained males and highly trained females, in particular in athletes who are competing in the same event or sport ${ }^{7}$, and especially regarding body composition ${ }^{8}$, has been existent for a long time.

An additional parameter in the analysis of fat-free mass in soccer players in particular is body cell mass ${ }^{9}$, defined as a metabolically active tissue in the body including muscle cells, organ cells, blood cells and immune cells ${ }^{10}$.

Studies performed in a localized lower limb analysis with dual-energy X-ray absorptiometry (DXA) and Bmode ultrasound show more body fat and less fat- 
free mass in adult female athletes compared with adult male athletes ${ }^{11,12}$.

An assessment of cell mass at the localized level can be done through bioimpedance analysis (BIA) in a male population of athletes ${ }^{13}$, but no data on female athletes are available using this methodology.

Women's sport, in Italy especially soccer, is gaining popularity. Currently coaches, athletic trainer and healthcare staff come from male sport: it is therefore necessary to provide information in order to treat female athletes following the physiology of each sex.

The aim of this study is to provide for the first time whole body and localized bioimpedance values in female elite soccer players.

A second aim is to confirm the differences between the sexes in terms of body composition using bioimpedance, both for whole body and localized evaluation at the lower limbs in elite soccer players.

\section{Material and methods}

\section{Study population}

Male and female elite soccer players of the same age were included in this study during the $2016-2017$ season. The inclusion criteria were: the elite athletes had to be Caucasian; they had to have been practicing soccer for at least ten years and competing for at least five years at an elite level; they had to belong to the same sports company to ensure similar training with the same workload and frequency; and they had to have the same lifestyle.

The exclusion criteria were: if they had sustained a muscle injury or had surgery in the lower limbs that compromised their muscle mass in the previous 24 months; and an age greater than 3 years in standard deviation.

Sample size was calculated to detect an effect size $(E S)=0.5$, with an estimated sample standard deviation $(S D)=7.0$, and a $S D$ for changes $=0.7$, requiring a minimum of 15 subjects per group. Power $(P=1-\beta)$ was set at 0.80 , and the confidence interval was $\alpha=$ 0.05 .

25 females and 43 males were recruited for this study: 7 females and 25 males were excluded. 18 elite female soccer players were matched with 18 elite male soccer players of the same age (female $=26.2 \pm 2.4$, male $26.9 \pm 2.5 ; p=0.87)$. All the enrolled athletes belonged to the same team in the same city; both the male and female athletes had a similar sports history and weekly physical workload; both sexes had practiced football for more than ten years and took part in at least five training sessions and one match per week: each session lasting about 2 hours during which both aerobic and anaerobic system are involved. All the subjects enrolled were movement players and non-goalkeepers. In detail, both samples consisted of 8 midfielders, 5 attackers and 5 defenders. These athletes were classified as elite because they were registered with the athletics federation at the maximum level (Italian Serie A for both sexes) and were receiving financial support for their full dedication to training and games.

The local ethics committee approved the study and therefore have been performed in accordance with the ethical standards laid down in the 1964 Declaration of Helsinki in addition the study meets the ethical standards of the journal ${ }^{14}$. All the participants signed their written informed consent prior to their inclusion in the study protocol.

\section{Body composition analysis}

The whole-body and cellular levels of analysis were both performed normally in clinical and research conditions:

- whole-body analysis considers the size and shape of the body; it divides the body into two compartments: fat mass and fat-free mass. The methods used for this level of analysis are body weight, height, circumference and skinfold thickness, with the Body Mass Index (BMI) and Fat Mass (FM) as the derived parameters;

- cellular level analysis divides the body into three compartments: cells, extracellular (plasma and interstitial fluid, organic and inorganic solids) and fat mass; a useful method was the analysis of human impedance.

All measurements were performed in the same place and by the same operator during the pre-participation screening for medical eligibility of 2016-2017 soccer season. A proper hydration status was verified by urine analysis performed in the early morning, the participants were subjected to body composition assessments in the same morning with no breakfast, no physical activity in the previous 12 hours and no long trips the previous day. On testing days, female athletes did not have the menstrual cycle as agreed with the club's sports physician.

The methodology used for the body composition assessment was in accordance with our previous study ${ }^{15}$, integrating anthropometry, circumferences, skinfold thickness, whole body bioelectrical impedance analysis and localized bioelectrical impedance.

\section{Anthropometry and circumferences}

Body mass was measured to the nearest $0.1 \mathrm{~kg}$ and height to the nearest $0.5 \mathrm{~cm}$. BMI measurement was calculated using the formula body mass [kg]/height $\left[\mathrm{m}^{2}\right]$. The circumference measurements were taken at the standard anatomical sites and could be used to determine body size and to monitor changes in these parameters ${ }^{16}$. The waist, hip and bicep circumferences were measured with a non-extendable metric tape which was flexible and accurate (Holtain Limited, $1.5 \mathrm{~m}$ Flexible Tape).

\section{Skinfold thickness}

Skinfold measurements are widely utilized to assess body fat mass. The same operator pinches the skin at the site to raise a double layer of skin and the underlying subcutaneous adipose tissue, but not the muscle. The calipers (Holtain, Limited Tanner/Whitehouse Skinfold Caliper) are then applied $1 \mathrm{~cm}$ below and at 
right angles to the pinch, and a reading is taken in millimetres $(\mathrm{mm})$. The measurements were performed at eight different anatomical sites around the body (triceps, biceps, sub-scapula, supra llium, mid-axilla, pectoral, abdominal, anterior thigh). The sum total of the eight sites (total skinfold) and their conversion into a percentage $(\mathrm{FM} \%)$ in kilograms of body fat were calculated. To convert the skinfold values from millimetres to a FM percentage, the average of the reported values was calculated using three different equations, as stated in the literature ${ }^{17-19}$. An additional parameter is the fat mass Index $\left(\mathrm{FMl}=\mathrm{FM} / \mathrm{h}^{2}\right.$ express as $\mathrm{kg} / \mathrm{m}^{2}$ ) in order to indexation for the different gender height. The fat-free mass (FFM) is calculated as body mass-fat mass, and the fat-free Mass Index is $\mathrm{FFM} / \mathrm{h}^{2}$ expressed as $\mathrm{kg} / \mathrm{m}^{2}$.

\section{Whole-body bioimpedance analysis (BIA) and vector analysis (BIVA)}

Whole-body impedance (BIA 101 Sport Edition, Akern, Florence, Italy) is generated in soft tissues to oppose the flow of an injected alternate current and is measured from skin $\mathrm{Ag} / \mathrm{AgCl}$ electrodes placed at fixed-distance $(5 \mathrm{~cm})$ on the hands and feet. The device emits an alternating sinusoidal electric current of $400 \mathrm{~mA}$ at an operating single frequency of $50 \mathrm{kHz}$ $( \pm 0.1 \%)$. Resistance $(R, \Omega)$ is the opposition to the flow of an injected alternating current, at any current frequency, through intra- and extracellular ionic solutions, while reactance $(\mathrm{Xc}, \Omega)$ is the dielectric or capacitive component of cell membranes and organelles, and tissue interfaces. Starting from these parameters, an estimate of the following body compartments parameters is derived: body cellular mass (BCM in $\mathrm{kg}$ ), extracellular mass (ECM in $\mathrm{kg}$ ), total body water (TBW in L), extracellular water (ECW, \% TBW), intracellular water (ICW, \% TBW). Additional parameters are body cell mass Index (BCMI) in $\mathrm{kg} / \mathrm{h}^{2}$ and total body water Index (TBWI) in $L / h^{2}$ in order to indexation for the different gender height.

To evaluate the hydration and cell mass independently of the estimation equations it was used bioelectrical impedance vector analysis (BIVA). BIVA is based on patterns on the resistance-reactance graph, where impedance is represented as a point on the RXc plane. Vector impedance ( $Z$ vector, $\Omega$ ) is represented as a point on the RXc plane and is a combination of vector length (VL, normalized per height of subject, $\Omega / \mathrm{m}$ ) and phase angle (PA in degrees, as the ratio between $\mathrm{R}$ and $\mathrm{Xc}$ or between the intra- and extracellular volumes). Therefore, changes in the impedance measurements reflect changes in the hydration and cell mass. Vector normalization according to a subject's height $(Z / h$, in $\Omega / m)$ was performed for different conductor lengths ${ }^{20}$.

\section{Localized bioimpedance vector analysis}

Localized bioelectrical impedance analysis may be useful for assessing body water to estimate the muscle volume in a limited segment of a limb ${ }^{21}$.

Electrode placements for localized bioimpedance measurements:
- right-femoral quadriceps and left-femoral quadriceps, in the supine position: 5 and $10 \mathrm{~cm}$ distally from the anterior inferior iliac spine and proximally from the superior pole of the patella;

- right hamstrings and left hamstrings, in the prone position: 5 and $10 \mathrm{~cm}$ distally from the ischiatic tuberosity and proximal from the popliteal line;

- right-calf muscles and left-calf muscles, in the prone position: 5 and $10 \mathrm{~cm}$ distally from the popliteal line and 15 and $10 \mathrm{~cm}$ from the posterior intermalleolar line.

In elite athletes, the muscle groups are bioelectrically symmetrical (right and left sides); therefore, the segmental values are considered to be the mean between the right and left sides ${ }^{13}$.

With the localized assessment being a vector evaluation, the parameters analyzed were $\mathrm{R}(\Omega)$ and $\mathrm{X}_{\mathrm{c}}(\Omega)$, normalized according to the segment length $(L, m)$, not the height of the subject ${ }^{13}$ :

Thigh: from the great trochanter to the knee joint space.

Leg: from the knee joint space to the external malleolus.

\section{Statistical analysis}

The data are expressed as mean \pm SD. The equality of the variances and the normality of the sample distribution were analyzed using Levene's test and a Shapiro-Wilk test, respectively. The comparison between the sexes was performed using an unpaired student's $t$ - test for continuous variables.

The analysis of the whole-body and muscle-localized bioimpedance vectors was performed using the RXc graph method 22: a. a BIVA point graph was used to plot the individual and mean whole-body vectors of our samples in the tolerance ellipses $(50,75$ and $95 \%$ ) of the healthy, general, reference population ${ }^{23}$ and the male, elite level, soccer reference population $^{24}$; b. a BIVA mean graph was used to compare: i. the whole-body mean vectors of the study samples with the healthy, general, reference population and the male, elite level, soccer reference population; II. the whole-body mean vectors of the female and male soccer samples; III. the quadricep, hamstring and calf vectors of our samples. The statistical associations between the adjusted BIA parameters $(\mathrm{R} / \mathrm{h}$ with $\mathrm{Xc} / \mathrm{h}$; $\mathrm{R} / \mathrm{L}$ with $\mathrm{Xc/L}$ ) were calculated using Pearson's correlation coefficient. A two-sample Hotelling's T2 test was used to determine the BIA vector differences between: a. the study samples vs the healthy, general, reference population and the male, elite level, soccer reference population; $b$. the female vs male sample; c. the quadriceps, hamstrings and calves of the study samples.

To estimate the relevance of the differences analyzed, the relative effect sizes (ES) were calculated using Cohen's $d^{25}$. According to Cohen, ES are defined as small $(\leq 0.20)$, medium $(\leq 0.50)$ and large $(\leq$ 0.80 ). The $P$ values are informed and $p<0.05$ was considered statistically significant. SPSS software version 21.0 (SPSS ${ }^{\circledR}$, Inc.) was used for the data management and statistical analysis. 


\section{Results}

\section{Anthropometric sex differences}

The anthropometric and skinfold data are shown in Table I. All the parameters were greater in the males with the exception of the hip circumference/height. The skinfold data show higher fat mass values and lower fat-free mass values in the female athletes compared with the male athletes.

\section{Whole-body BIVA sex differences}

The bioimpedance variables (Tab. II) show greater parameters in the males for both cell mass and hydration level. The lowest value of $\mathrm{R}$ proves the highest water content in males. Regarding water distribution, the female athletes show a higher percentage of extracellular water: the higher Xc value in the females is reported in body composition values as no difference in ECM when indexed according to percentage of body mass or $\mathrm{kg} / \mathrm{m}^{2}$ (Fig. 1).

The BIVA point graph (Fig. 2) indicates that the female and male soccer players fell mostly outside the $50 \%$ tolerance ellipse and in the upper left sector (typically representing the athletes' quadrant) their healthy, general reference populations. A better adjustment of the male soccer players was found when they were plotted in the male, soccer reference population (Fig. 2), also detected by the non-significant vector difference $\left(T^{2}=3.3 ; p=0.194\right)$ in their $95 \%$ confidence ellipses (Fig. 3). Differences in the wholebody BIA vector compared with the healthy, general reference populations were found for the female $\left(T^{2}=45.0, p=0.0001\right)$ and male soccer players $\left(T^{2}\right.$
46.6, $\mathrm{p}=0.0001$ ), as well as between both groups of soccer players $\left(\mathrm{T}^{2}=91.7, \mathrm{p}=0.0001\right)$, (Fig. 3$)$.

\section{Localized BIVA sex differences}

The localized bioimpedance assessment (Tab. III) shows longer lower limbs in the males. The vector is longer in the females and the PA is greater in the males; these differences tend to decrease from the thighs to the calves: at the gastrocnemius the $\mathrm{Xc}_{\mathrm{c}}$ values become higher in the females.

The adjusted BIA muscle-localized values of $Q, H$ and $C$ in both soccer samples are shown in Table III. Significant differences were found in all the variables between the female and male samples. R/L and $Z$ were significantly higher in the female players for all the muscles. In the case of $\mathrm{Xc} / \mathrm{L}$ and $\mathrm{PA}$, almost all the muscles reported significantly lower values in the female players (only the calves had higher values of $\mathrm{Xc} / \mathrm{L}$ ).

The BIVA mean graph (Fig. 4) shows significant differences in the BIA muscle-localized bivariate vectors between a. female vs male $\mathrm{Q}, \mathrm{H}$ and $\mathrm{C}\left(\mathrm{Q}\right.$ : $\mathrm{T}^{2}=182.4 ; \mathrm{H}$ : $\left.\mathrm{T}^{2}=68.9 ; \mathrm{C}: \mathrm{T}^{2}=38.8, \mathrm{p}=0.0001\right) ; \mathrm{b}$. female and male $\mathrm{Q}$ vs C (female: $\mathrm{T}^{2}=228.0$; male: $\mathrm{T}^{2}=289.9 ; \mathrm{p}=0.0001$ ); . female and male $\mathrm{H}$ vs $\mathrm{C}$ (female: $\mathrm{T}^{2}=290.1$; male: $\left.\mathrm{T}^{2}=233.3 ; \mathrm{p}=0.0001\right)$; female $\mathrm{Q}$ vs $\mathrm{H}\left(\mathrm{T}^{2}=8.9 ; \mathrm{p}=0.02\right)$. There were no significant differences between $Q$ and $H$ in the male sample $\left(\mathrm{T}^{2}=1.2, \mathrm{p}=0.57\right)$.

\section{Discussion}

Soccer is a sport with a high dynamic component ${ }^{26}$, the sample in this study had practiced football at the

Table I. Sex comparison in anthropometrics and skinfold parameters. BMI, body mass index; Hip c, hip circumference; Waist c, waist circumference; Arm c, arm circumference; FMI, fat mass index; FFMI, fat-free mass index; a, large effect size ( $d \leq 0.8)$.

\begin{tabular}{|c|c|c|c|c|c|}
\hline & $\begin{array}{c}\text { Female }_{(95 \% \mathrm{cl})} \\
\quad(\mathrm{n}=\mathbf{1 8})\end{array}$ & $\begin{array}{c}\text { Male }_{(95 \% \mathrm{Cl})} \\
\quad(\mathrm{n}=\mathbf{1 8})\end{array}$ & $\begin{array}{c}\text { Student's } \\
t \text {-test }(t)\end{array}$ & $\begin{array}{c}p \text {-value } \\
(p)\end{array}$ & $\begin{array}{c}\text { Cohen's d } \\
\text { (d) }\end{array}$ \\
\hline Height $(\mathrm{cm})$ & $168.6 \pm 6.9_{(165.1-172.0)}$ & $182.2 \pm 6.9_{(178.7-185.6)}$ & -5.903 & 0.0001 & $1.97^{\mathrm{a}}$ \\
\hline Body mass $(\mathrm{kg})$ & $61.0 \pm 7.7_{(57.2-64.8)}$ & $77.9 \pm 6.6_{(74.6-81.2)}$ & -7.056 & 0.0001 & $2.35^{\mathrm{a}}$ \\
\hline $\operatorname{BMI}\left(\mathrm{kg} / \mathrm{m}^{2}\right)$ & $21.4 \pm 1.9(20.5-22.4)$ & $23.5 \pm 1.2(22.9-24.0)$ & -3.939 & 0.001 & $1.31^{\mathrm{a}}$ \\
\hline Waist c. $(\mathrm{cm})$ & $67.6 \pm 5.2(65.1-70.2)$ & $77.3 \pm 3.6_{(75.4-79.1)}$ & -6.446 & 0.0001 & $2.15^{\mathrm{a}}$ \\
\hline Waist c./Height & $40.1 \pm 2.2(39.0-41.2)$ & $42.5 \pm 2.3(41.3-43.6)$ & $-3,106$ & 0.004 & $1.04^{\mathrm{a}}$ \\
\hline Hip c. (cm) & $92.9 \pm 4.4(90.7-95.1)$ & $95.1 \pm 3.6_{(93.3-96.9)}$ & -1.653 & 0.108 & $0.55^{\mathrm{a}}$ \\
\hline Hip c./Height & $55.2 \pm 2.7_{(53.8-56.5)}$ & $52.3 \pm 1.6_{(51.4-53.1)}$ & 3,892 & 0.001 & $1.30^{\mathrm{a}}$ \\
\hline Arm c. $(\mathrm{cm})$ & $25.4 \pm 2.4$ & $29.1 \pm 1.5(28.4-29.8)$ & -5.646 & 0.0001 & $1.88^{\mathrm{a}}$ \\
\hline Sum skin fold (mm) & $88.6 \pm 17.4(79.9$ - 97.3) & $56.4 \pm 8.7_{(52.0-60.7)}$ & 7.020 & 0.0001 & $2.34^{a}$ \\
\hline Fat mass (\%) & $16.6 \pm 2.9_{(15.2-18.0)}$ & $10.3 \pm 1.5$ & 8.191 & 0.0001 & $2.73^{\mathrm{a}}$ \\
\hline $\mathrm{FMI}\left(\mathrm{kg} / \mathrm{m}^{2}\right)$ & $3.7 \pm 0.7_{(3.4-4.1)}$ & $2.4 \pm 0.4(2.2-2.6)$ & 6.878 & 0.0001 & $2.29^{\mathrm{a}}$ \\
\hline Fat-free mass $(\mathrm{kg})$ & $50.4 \pm 5.7(47.5-53.2)$ & $69.9 \pm 5.7(67.0-72.7)$ & -10.242 & 0.0001 & $3.41^{\mathrm{a}}$ \\
\hline FFMI $\left(\mathrm{kg} / \mathrm{m}^{2}\right)$ & $17.7 \pm 1.5(17.0-18.5)$ & $21.0 \pm 0.9$ & -7.997 & 0.0001 & $2.67^{\mathrm{a}}$ \\
\hline
\end{tabular}


Table II. Comparison between genders in bioimpedance analysis. R/h, ratio between resistance and height; Xc/h, ratio between reactance and height; $\mathrm{PA}$, phase angle; $\mathrm{BCM}$, body cell mass; $\mathrm{BCMI}$, body cell mass index; $\mathrm{ECM}$, extracellular mass; ECMI, extracellular mass index; TBW, total body water; TBWI, total body water index; ICW, intracellular water; ECW, extracellular water; a, large effect size ( $d \leq 0.8)$.

\begin{tabular}{|c|c|c|c|c|c|}
\hline & $\begin{array}{l}\text { Female }_{(95 \% ~ C l)} \\
\quad(n=18)\end{array}$ & $\begin{array}{l}\text { Male }_{(95 \% ~ C l)} \\
(\mathbf{n}=18)\end{array}$ & $\begin{array}{l}\text { Student' } \\
t \text {-test }(t)\end{array}$ & $\begin{array}{c}p \text {-value } \\
(p)\end{array}$ & $\begin{array}{c}\text { Cohen's d } \\
\text { (d) }\end{array}$ \\
\hline $\mathrm{R} / \mathrm{h}(\Omega / \mathrm{m})$ & $329.3 \pm 28.5_{(315.1-343.4)}$ & $254.2 \pm 18.6_{(244.9-263.5)}$ & 9.365 & 0.0001 & $3.12^{\mathrm{a}}$ \\
\hline $\mathrm{Xc} / \mathrm{h}(\Omega / \mathrm{m})$ & $41.0 \pm 4.2_{(39.0-43.1)}$ & $35.3 \pm 2.9_{(33.8-36.7)}$ & 4.828 & 0.0001 & $1.61^{\mathrm{a}}$ \\
\hline $\operatorname{PA}\left({ }^{\circ}\right)$ & $7.1 \pm 0.5(6.9-7.4)$ & $7.9 \pm 0.5(7.7-8.1)$ & -4.538 & 0.0001 & $1.51^{\mathrm{a}}$ \\
\hline $\mathrm{BCM}(\mathrm{kg})$ & $28.2 \pm 2.6_{(26.9-29.5)}$ & $41.0 \pm 3.4_{(39.3-42.6)}$ & -12.810 & 0.0001 & $4.27^{\mathrm{a}}$ \\
\hline $\operatorname{BCMI}\left(\mathrm{kg} / \mathrm{m}^{2}\right)$ & $10.0 \pm 1.0_{(9.5-10.6)}$ & $12.4 \pm 0.9_{(11.9-12.8)}$ & -7.024 & 0.0001 & $2.34^{\mathrm{a}}$ \\
\hline ECM (kg) & $20.2 \pm 3.6_{(18.4-22.0)}$ & $25.1 \pm 1.9_{(24.2-26.1)}$ & -5.163 & 0.0001 & $1.72^{\mathrm{a}}$ \\
\hline $\operatorname{ECMI}\left(\mathrm{kg} / \mathrm{m}^{2}\right)$ & $7.1 \pm 1.2(6.5-7.7)$ & $7.6 \pm 0.4(7.4-7.8)$ & -1.659 & 0.106 & $0.55^{\mathrm{a}}$ \\
\hline TBW (I) & $35.0 \pm 3.1_{(33.4-36.5)}$ & $48.2 \pm 3.5(46.4-49.9)$ & -12.036 & 0.0001 & $4.01^{a}$ \\
\hline TBWI $\left(I / \mathrm{m}^{2}\right)$ & $12.3 \pm 0.8(11.9-12.7)$ & $14.5 \pm 0.8(14.1-14.9)$ & -8.030 & 0.0001 & $2.68^{a}$ \\
\hline ICW (\%) & $58.9 \pm 2.0_{(57.9-59.9)}$ & $61.6 \pm 1.6_{(60.9-62.4)}$ & -4.522 & 0.0001 & $1.51^{\mathrm{a}}$ \\
\hline ECW (\%) & $41.2 \pm 2.0_{(40.2-42.2)}$ & $38.4 \pm 1.6(37.6-39.1)$ & 4.609 & 0.0001 & $1.54^{\mathrm{a}}$ \\
\hline
\end{tabular}

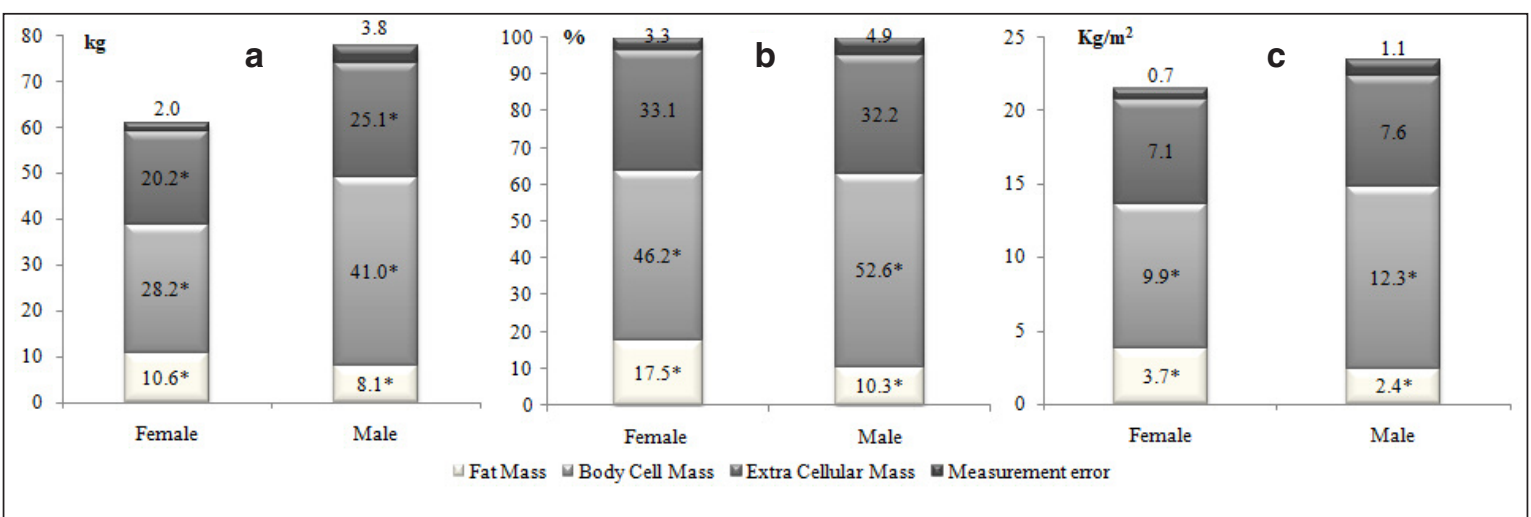

Figure 1. Sexes differences in body composition with three compartments model indexed by body weight, percentage of body weight and by $\mathrm{kg} / \mathrm{m}^{2}$. a. On the left side, body composition analysis with three compartments model divided by $\mathrm{kg}$ of body mass; b. on the middle, body composition analysis with three compartments model divided by \% of body mass; c. on the right side, body composition analysis with three compartments model divided by $\mathrm{kg} / \mathrm{m}^{2}$. Measurement error $=$ difference between the sum of three compartment data of body composition and body weight or percentage of body weight or $\mathrm{kg} / \mathrm{m}^{2}$.

* Sex differences with $p<0.05$.

highest professional levels for at least five years. Therefore, their body composition should be considered stable: our data, obtained through a non-gold standard method, confirm differences between the sexes in whole and localized body compositions ${ }^{11}$, as well as in highly trained subjects competing in the same sport. In particular, the literature about localized bioimpedance mainly represents male athletes: this study reports for the first time localized bioimpedance parameters in female athletes.

This study has some peculiarities: firstly, and as mentioned previously, all the athletes belonged to the same team, trained with the same workload and frequency, and had the same lifestyle. Thus, sex was the only differential element between the athletes, who were matched according to their ethnicity, mean age and clinical characteristics, any possible differences in the results related to these determinants being deleted. This made it possible to evaluate specifically the contribution of gender to body composition variables in elite athletes. A second unique characteristic was the evaluation of the role of soccer in determining body composition adaptations.

However, this study has some limitations. The first limitation is that bioimpedance techniques have some limitations but remain the main method to asses body cell mass. Second, in a whole-body assessment, the absence of specific tolerance ellipses for a female 

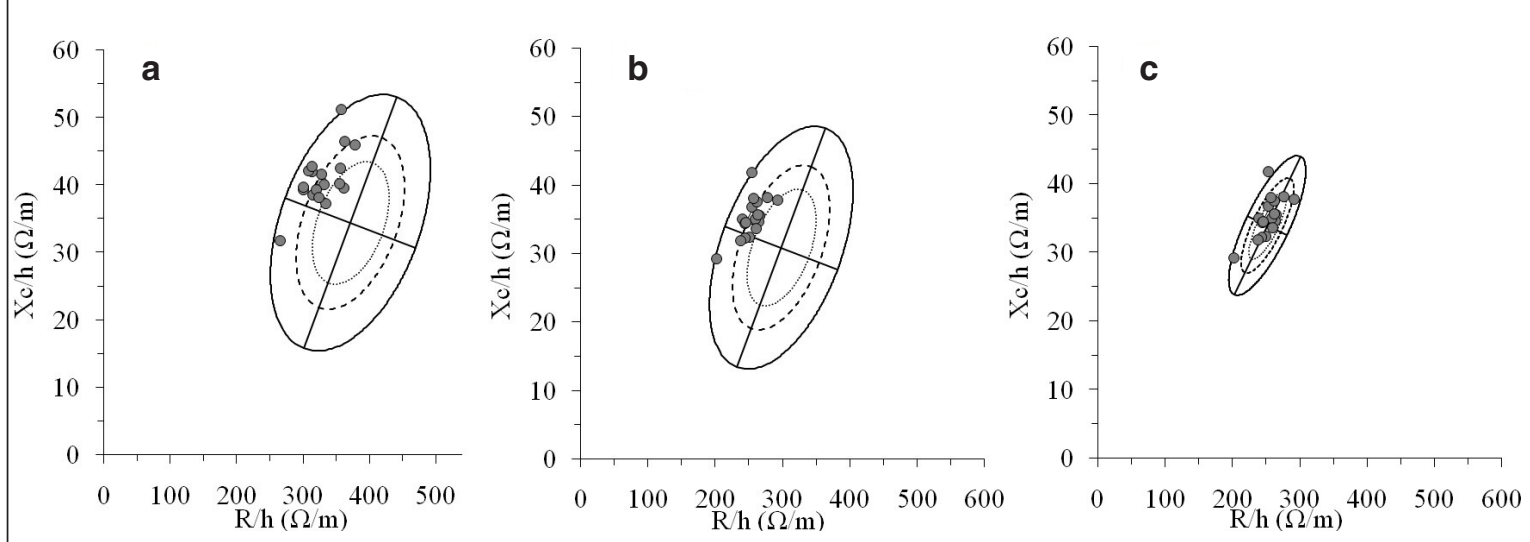

Figure 2 Whole-body BIVA point graphs. a. On the left side, the female sample plotted on the tolerance ellipses of the reference population ${ }^{21} ; \mathrm{b}$. on the middle, the male sample plotted on the tolerance ellipses of the reference population ${ }^{21}$; c. on the right side, the male sample plotted on the tolerance ellipses of the male, elite level, soccer reference population ${ }^{22}$. R/h, height-adjusted resistance; Xc/h, height-adjusted reactance.

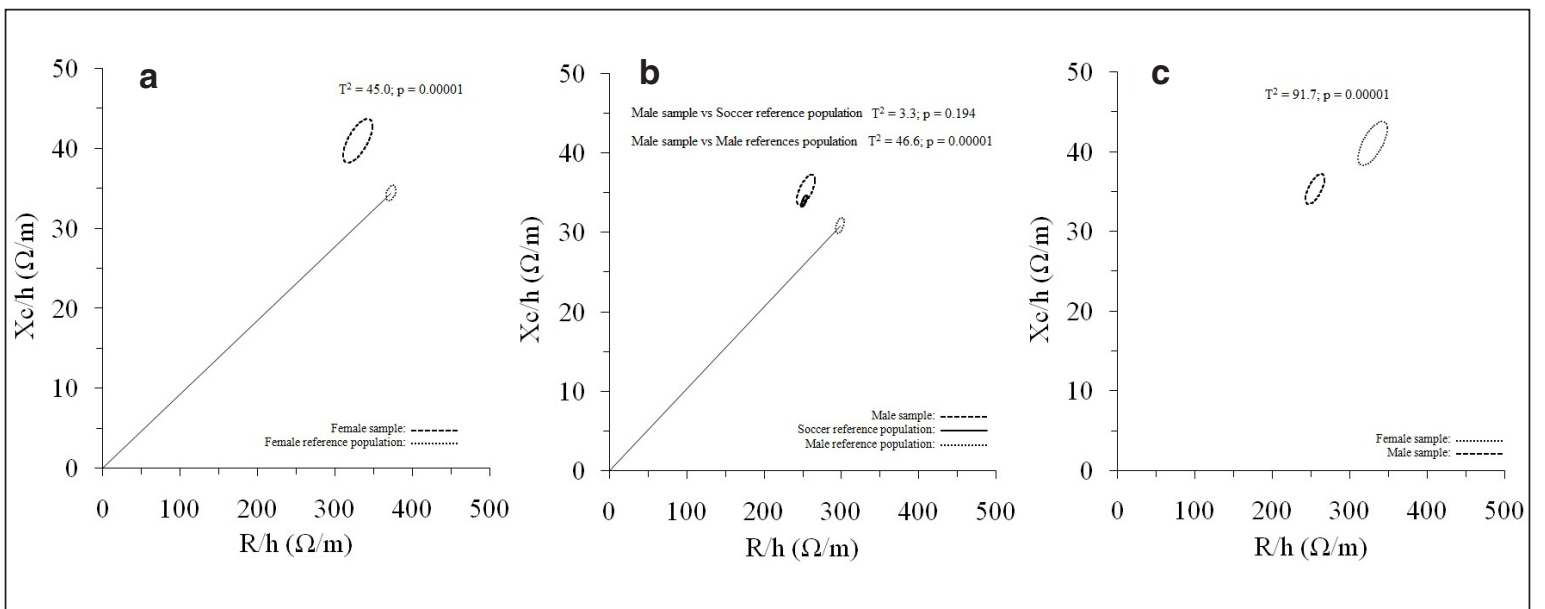

Figure 3. Whole-body BIVA mean graph. a. The $95 \%$ confidence ellipses for the whole-body mean impedance vectors of the female sample (dark dashed line ellipse) and the reference population (dotted line ellipse with vector) are shown ${ }^{21}$; b. The $95 \%$ confidence ellipses for the whole-body mean impedance vectors of the male sample (dark dashed line ellipse), the reference population (dotted line ellipse with vector) ${ }^{21}$ and the soccer reference population ${ }^{22}$ are shown; c. the $95 \%$ confidence ellipses for the whole-body mean impedance vectors of the female sample (dotted line ellipse) and the male sample (dark dashed line ellipse) are shown. R/h, height-adjusted resistance; Xc/h, height-adjusted reactance.

athlete population does not allow a comparison between this sample and a specific sports population, although the data from the present study can help create one. Third, in localized analysis, bioimpedance des not allow an assessment of the lean mass/fat mass ratio, although in an athlete population BIVA allows a quick and repeatable evaluation of the health of muscle cells.

The differences between the sexes in body composition are well established in the literature ${ }^{27}$; differences in fat mass and in body cell mass can also be found in athletes who compete in the same sport, possibly due to their different adaptions, also mediat- ed by hormonal status, to the same kind of physical effort ${ }^{28}$. This study confirms a higher fat mass percentage in adult female athletes ${ }^{11}$; indexing to the height of the body composition parameters allowed us to show an increased hip circumference.

In addition, no differences between the sexes in terms of extracellular mass were observed: these are the metabolically inactive parts of the body's components, including bones, minerals, blood plasma and water contained outside living cells, where hormonal action is limited.

The three-compartment model allows an integration of the two different methods: skinfold thickness to 
Table III. Comparison between gender in localized Bioimpedance analysis. L, segment length; R/L, ratio between resistance and segment length; Xc/L, ratio between reactance and segment length; PA, phase angle; VL, vector length; $a$, large effect size ( $d \leq 0.8)$.

\begin{tabular}{|c|c|c|c|c|c|}
\hline & $\begin{array}{c}\text { Female }_{(95 \% \mathrm{Cl})} \\
(\mathrm{n}=\mathbf{1 8})\end{array}$ & $\begin{array}{c}\text { Male }_{(95 \% \mathrm{Cl})} \\
(\mathrm{n}=18)\end{array}$ & $\begin{array}{c}\text { T-Student test } \\
(t)\end{array}$ & $\begin{array}{c}p \text {-value } \\
(p)\end{array}$ & $\begin{array}{l}\text { Cohen's d } \\
\text { (d) }\end{array}$ \\
\hline \multicolumn{6}{|l|}{ Quadriceps } \\
\hline Thigh L (m) & $0.54 \pm 0.03_{(0.52-0.56)}$ & $0.43 \pm 0.03_{(0.42-0.45)}$ & 9.510 & 0.0001 & $3.17^{\mathrm{a}}$ \\
\hline $\mathrm{R} / \mathrm{L}(\Omega / \mathrm{m})$ & $134.4 \pm 15.0{ }_{(126.9-141.8)}$ & $107.6 \pm 11.9_{(101.7-113.6)}$ & 5.917 & 0.0001 & $1.97^{\mathrm{a}}$ \\
\hline $\mathrm{Xc} / \mathrm{L}(\Omega / \mathrm{m})$ & $19.0 \pm 4.2_{(16.9-21.1)}$ & $26.4 \pm 4.8_{(24.0-28.7)}$ & -4.938 & 0.0001 & $1.65^{\mathrm{a}}$ \\
\hline $\mathrm{PA}\left(\left(^{\circ}\right)\right.$ & $8.8 \pm 2.0_{(7.8-9.8)}$ & $14.1 \pm 2.1_{(13.1-15.2)}$ & -7.827 & 0.0001 & $2.61^{a}$ \\
\hline $\mathrm{VL}(\Omega / \mathrm{m})$ & $135.3 \pm 15.4(127.6-142.9)$ & $111.4 \pm 13.1_{(104.9-117.9)}$ & 5.009 & 0.0001 & $1.67^{a}$ \\
\hline \multicolumn{6}{|l|}{ Hamstrings } \\
\hline $\mathrm{R} / \mathrm{L}(\Omega / \mathrm{m})$ & $118.8 \pm 16.4_{(110.7-127.0)}$ & $104.9 \pm 11.4(99.3-110.6)$ & 2.962 & 0.006 & $0.99^{a}$ \\
\hline $\mathrm{Xc} / \mathrm{L}(\Omega / \mathrm{m})$ & $18.2 \pm 2.6_{(16.9-19.4)}$ & $26.9 \pm 4.2(24.9-29.0)$ & -7.574 & 0.0001 & $2.53^{\mathrm{a}}$ \\
\hline $\operatorname{PA}\left({ }^{\circ}\right)$ & $8.9 \pm 1.8_{(7.9-9.8)}$ & $14.5 \pm 2.7_{(13.2-15.9)}$ & -7.428 & 0.0001 & $2.48^{a}$ \\
\hline $\operatorname{VL}(\Omega / m)$ & $120.3 \pm 16.2(112.2-128.3)$ & $108.4 \pm 11.0_{(102.9-113.9)}$ & 2.568 & 0.02 & $0.86^{a}$ \\
\hline \multicolumn{6}{|l|}{ Calves } \\
\hline $\operatorname{Leg} L(m)$ & $0.42 \pm 0.03(0.41-0.44)$ & $0.46 \pm 0.04_{(0.45-0.48)}$ & -3.947 & 0.0001 & $1.32^{\mathrm{a}}$ \\
\hline $\mathrm{R} / \mathrm{L}(\Omega / \mathrm{m})$ & $225.9 \pm 27.7(212.2-239.7)$ & $182.1 \pm 18.2_{(173.0-191.1)}$ & 5.621 & 0.0001 & $1.87^{\mathrm{a}}$ \\
\hline $\mathrm{Xc} / \mathrm{L}(\Omega / \mathrm{m})$ & $52.6 \pm 8.7_{(48.3-56.9)}$ & $45.8 \pm 7.0_{(42.3-49.2)}$ & 2.612 & 0.01 & $0.87^{\mathrm{a}}$ \\
\hline $\operatorname{PA}\left({ }^{\circ}\right)$ & $13.1 \pm 1.5_{(12.3-13.8)}$ & $14.0 \pm 1.1_{(13.5-14.6)}$ & -2.173 & 0.03 & $0.72^{\mathrm{a}}$ \\
\hline $\operatorname{VL}(\Omega / m)$ & $232.12 \pm 8.4(217.9-246.2)$ & $183.4 \pm 19.1$ & 5.492 & 0.0001 & $1.83^{\mathrm{a}}$ \\
\hline
\end{tabular}

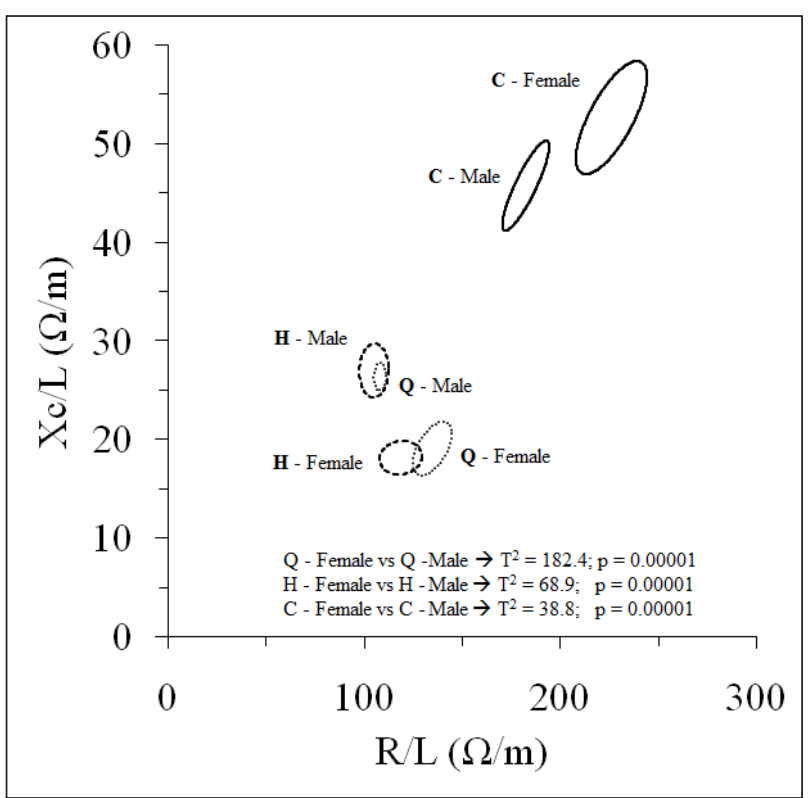

evaluate fat mass and bioimpedance analysis to assess fat-free mass. Therefore, a certain degree of measurement error (Fig. 1 b report $3.3 \%$ in females and $4.9 \%$ in males) is expected. That observed in the present study appears to be approximately the same
Figure 4. Muscle-localized BIVA mean graph. The 95\% confidence ellipses for the muscle-localized mean impedance vectors of the female and male samples are shown. Q, quadriceps (dotted line ellipse); $\mathrm{H}$, hamstrings (dark dashed line ellipse); C, calves (solid line ellipse); R/L, segment length-adjusted resistance; Xc/L, segment. as, or lower than, those observed in previous studies ${ }^{15}$. In addition, the three-compartment model of body composition shows how differences between the sexes in the extracellular compartment are dismissed with correct indexing. 
A shift to the left in the whole-body BIVA evaluation was observed for both the male and female samples compared to the healthy general reference populations, something already observed in the literature ${ }^{24,29}$, possibly reflecting athletes' specific body composition due to increased soft tissue mass and different fluid content. Therefore, BIVA would be sensitive to this specific body composition of sports samples, highlighting the necessity of generating new specific tolerance ellipses.

The literature reports differences in localized body composition ${ }^{11}$, but these differences tend to decrease if a comparison is made between those body parts under the most stress from sports ${ }^{30}$. Localized bioimpedance shows differences in all the thigh parameters. In particular, female soccer players have less water and fewer cells compared with male soccer players. In the calves the differences show higher Xc values in female athletes: the calf is the body part most used for soccer-related activities such as walking, running and jumping.

The literature about localized bioimpedance describes changes due to training ${ }^{11,13}$ or muscle injuries ${ }^{31,32}$; the results of these studies show comparable data. In particular, reductions in both the $R$ and Xc parameters in case of muscle injury are described, while for training only the $\mathrm{R}$ value decreases.

Future research areas will be to increase the number of subjects evaluated performing a localized assessment either in the general population and in a sportspecific population in order to describe a further differentiation in their adaption to specific training, especially in a localized analysis between the sexes.

Applicability of localized bioimpedance in the field, especially in elite athletes, should be represented as an initial assessment: these data provide an additional parameter in the evaluation of the training level or during the return-to-play phase after a sports injury.

\section{Conclusion}

The three-compartment model in this study of body composition shows similarities between the sexes in extracellular mass, where hormonal activity has a similar action between male and female young adults. For the first time, localized lower-limb impedance parameters are described in female elite athletes. This may be useful for the further assessment of athletes during a competitive season.

\section{References}

1. Ackland TR, Lohman TG, Sundgot-Borgen J, Maughan RJ, Meyer NL, Stewart AD, Müller W. Current status of body composition assessment in sport: review and position statement on behalf of the ad hoc research working group on body composition health and performance. under the auspices of the IOC Medical Commission. Sports Med. 2012;42(3):227249. doi: 10.2165/11597140-000000000-00000.

2. Sundgot-Borgen J, Meyer NL, Lohman TG, Ackland TR, Maughan RJ, Stewart AD, Müller W. How to minimise the health risks to athletes who compete in weight-sensitive sports review and position statement on behalf of the Ad Hoc Research Working Group on Body Composition, Health and Performance, under the auspices of the IOC Medical Commission. Br J Sports Med. 2013 Nov;47(16):1012-1022. doi: 10.1136/bjsports-2013-092966.

3. Meyer NL, Sundgot-Borgen J, Lohman TG, Ackland TR, Stewart AD, Maughan RJ, Smith S, Müller W. Body composition for health and performance: a survey of body composition assessment practice carried out by the Ad Hoc Research Working Group on Body Composition, Health and Performance under the auspices of the IOC Medical Commission. Br J Sports Med. 2013 Nov;47(16):1044-1053. doi: 10.1136/bjsports-2013-092561

4. Malina RM. Body composition in athletes: assessment and estimated fatness Clin Sports Med. 2007;26(1):37-68.

5. Jeukendrup A, Gleeson M, Sport Nutrition-2 ${ }^{\text {nd }}$ Edition Champaign. II. Human Kinetics. 2010.

6. Charkoudian N, Joyner MJ. Physiologic considerations for exercise performance in women. Clin Chest Med. 2004;25 (2):247-255

7. Wilmore $\mathrm{JH}$. The application of science to sport: physiological profiles of male and female athletes. Can J Appl Sport Sci. 1979;4(2):103-115.

8. Lewis DA, Kamon E, Hodgson JL. Physiological differences between genders. Implications for sports conditioning. Sports Med. 1986;3(5):357-369.

9. Mascherini G, Gatterer H, Lukaski H, Burtscher M, Galanti G. Changes in hydration. Body-cell mass and endurance performance of professional soccer players through a competitive season. J Sports Med Phys Fitness. 2015;55 $(7,8): 749-755$.

10. Moore FD, Boyden CM. Body cell mass and limitations of hydration of fat free body: their relation to estimated skeletal weight. Ann NY Acad Sci. 1963;26;110:62-71.

11. Santos DA, Dawson JA, Matias CN, Rocha PM, Minderico CS, Allison DB, Sardinha LB, Silva AM. Reference values for body composition and anthropometric measurements in athletes. PLoS One. 2014;15;9(5):e97846.

12. Abe T, Brechue WF, Fujita S, Brown JB. Gender differences in FFM accumulation and architectural characteristics of muscle. Med Sci Sports Exerc. 1998;30(7):10661070.

13. Nescolarde L, Yanguas J, Medina D, Rodas G, Rosell-Ferrer J. Assessment and follow-up of muscle injuries in athletes by bioimpedance: preliminary results. Conf Proc IEEE Eng Med Biol Soc. 2011;1137-1140.

14. Padulo J, Oliva F, Frizziero A, Maffulli N. Muscles, Ligaments and Tendons Journal - Basic principles and recommendations in clinical and field science research: 2016 update. MLTJ. 2016;6(1):1-5.

15. Mascherini G, Petri C, Galanti G. Integrated total body composition and localized fat-free mass assessment. Sport Sci Health. 2015;11(2):217-225. doi:10.1007/s11332-015-0228-y

16. Marfell-Jones MJ, Stewart AD, de Ridder JH. International standards for anthropometric assessment. Wellington. New Zealand: International Society for the Advancement of Kinanthropometry. 2012.

17. Durnin JV, Womersley J. Body fat assessed from total body density and its estimation from skinfold thickness: measurements on 481 men and women aged from 16 to 72 years. Br J Nutr. 1974;32(1):77-97.

18. Jackson AS, Pollock ML, Gettman LR. Intertester reliability of selected skinfold and circumference measurements and percent fat estimates. Res Q. 1978;49(4):546-551.

19. Oliver JM, Lambert BS, Martin SE, Green JS, Crouse SF. Predicting football players' dual-energy $x$-ray absorptiometry body composition using standard anthropometric mea- 
Differences between the sexes in athletes' body composition and lower limb bioimpedance values

sures. J Athl Train. 2012;47(3):257-263.

20. Kyle UG, Bosaeus I, De Lorenzo AD, Deurenberg P, Elia M, Gomez JM, Heitmann BL, Kent-Smith L, Melchior JC, Pirlich M, Scharfetter H, Schols AMWJ, Pichard C. Bioelectrical impedance analysis-part II: utilization in clinical practice. Clin Nutr. 2004;23:1430-1453.

21. Lorenzo AD, Andreoli A. Segmental bioelectrical impedance analysis. Curr Opin Clin Nutr Metab Care. 2003;6(5):551-555.

22. Piccoli A, Pastori G. BIVA software. Padova: Department of Medical and Surgical Sciences, University of Padova, Italy. 2002.

23. Piccoli A, Nigrelli S, Caberlotto A, Bottazzo S, Rossi B, PilIon $\mathrm{L}$, Maggiore $\mathrm{Q}$. Bivariate normal values of the bioelectrical impedance vector in adult and elderly populations. Am J Clin Nutr. 1995;61:269-270.

24. Micheli ML, Pagani L, Marella M, Gulisano M, Piccoli A, Angelini $F$, Burtscher M, Gatterer H. Bioimpedance and impedance vector patterns as predictors of league level in male soccer players. Int J Sports Physiol Perform. 2014;9 (3):532-539.

25. Cohen J. A power primer. Psychol Bull. 1992;112(1):155 159.

26. Mitchell JH, Haskell W, Snell P. Van Camp SP. Task Force 8: Classification of sports. J Am Coll Cardiol. 2005;45(8): 1364-1367.

27. Schweiz Z. Sport anthropological knowledge of relationship between individual hormone levels and anthropometric measuring values Sportmed. 1993;41(2):67-74

28. Sartorio A, Agosti F, Marazzi N, Trecate L, Silvestri G, Lafortuna C, Cappa M, De Palo E, Faglia G, Corradini C, Cella S, Rigamonti A, Müller EE. Gender-, age-, body composition- and training workload-dependent differences of $\mathrm{GH}$ response to a discipline-specific training session in elite athletes: A study on the field. J Endocrinol Invest. 2004;27 (2): $121-129$

29. Carrasco-Marginet M, Castizo-Olier J, Rodríguez-Zamora L, Iglesias X, Rodríguez FA, Chaverri D, Brotons D, Irurtia A. Bioelectrical impedance vector analysis (BIVA) for measuring the hydration status in young elite synchronized swimmers. PLoS One. 2017;7;12(6):e0178819. doi: 10.1371/ journal.pone.0178819. eCollection 2017.

30. Bishop P, Cureton K, Conerly M, Collins M. Sex difference in muscle cross-sectional area of athletes and non-athletes. J Sports Sci. Spring. 1989;7(1):31-39.

31. Nescolarde L, Yanguas J, Lukaski H, Alomar X, Rosell-Ferrer J, Rodas G. Effects of muscle injury severity on localized bioimpedance measurements. Physiol Meas. 2015;36(1):2742. doi: 10.1088/0967-3334/36/1/27.

32. Nescolarde L, Yanguas J, Lukaski H, Alomar X, Rosell-Ferrer J, Rodas G. Localized bioimpedance to assess muscle injury. Physiol Meas. 2013;34(2):237-245. doi: 10.1088/ 0967-3334/34/2/237. 